\title{
Observational Analysis of Changes in Endotracheal Tube Cuff Pressure During Laparoscopic Surgery
}

\author{
Hunsehalli Revanasiddappa Narendra ${ }^{1}$, Aparna Nerurkar ${ }^{2}$, Shibu Sasidharan ${ }^{3}$
}

\begin{abstract}
Background: Laparoscopic surgery is performed under general anesthesia with mechanical ventilation, and a high-volume, low-pressure endotracheal tube (ETT) with a sealing cuff pressure about $20-30 \mathrm{~cm}$ of $\mathrm{H}_{2} \mathrm{O}$ is commonly used for a proper seal and avoidance of overinflation. Nitrous oxide $\left(\mathrm{N}_{2} \mathrm{O}\right)$ is an inhalational anesthetic that is used with oxygen in the ratio 50:50 for the maintenance of anesthesia if there is no facility of medical air. However, $\mathrm{N}_{2} \mathrm{O}$ increases the intracuff pressure of the tracheal tube due to diffusion of $\mathrm{N}_{2} \mathrm{O}$ in to cuff during general anesthesia. The present research was done to study the cuff pressure changes during laparoscopic surgeries with $\mathrm{N}_{2} \mathrm{O}$ anesthesia and to assess its variation during the various stages of surgery and also its correlation with position of the patient.

Materials and methods: A study was done in a tertiary-level hospital over a period of 1 year in 70 patients undergoing laparoscopic surgery. Endotracheal tube was inflated with incremental doses of $0.5 \mathrm{~mL}$ of air to a point where no leak on auscultation on the suprasternal area was noted. Cuff pressure measurement using cuff pressure monitor (Hand pressure gauge) was done at the time of first inflation of cuff up to 20-30 $\mathrm{cm}$ of $\mathrm{H}_{2} \mathrm{O}$ and airway pressure, along with total amount of air inflated was noted as "zero" reading. Thereafter, cuff pressure was measured at regular interval of 5 minutes. Cuff pressures and airway pressures were taken just prior to insufflation, 2 minutes after abdominal insufflation, thereafter every 15 minutes throughout surgery, and 2 minutes after desufflation and prior to extubation.

Results: Out of 70 patients, maximum patients were of the age-group of $20-50$ years $(78.5 \%)$. There was no statistically significant difference between the groups. Cuff pressure at the induction was kept in range of $20-30 \mathrm{~cm}$ of $\mathrm{H}_{2} \mathrm{O}$. In this study, mean tracheal cuff pressure at baseline was $21.10+6.16$ ( $p$ value of 0.207 ) and prior to insufflation was $21+7.13$ ( $p$ value of 0.733 ). The cuff pressures at 2 minutes post insufflation (P2), P15, P30, P45, and P60 were $31.40 \pm 12.54 \mathrm{~cm}$ of $\mathrm{H}_{2} \mathrm{O}, 25.79 \pm 8.68 \mathrm{~cm}$ of $\mathrm{H}_{2} \mathrm{O}, 24.61 \pm 7.37 \mathrm{~cm}$ of $\mathrm{H}_{2} \mathrm{O}, 23.83 \pm 9.43 \mathrm{~cm}$ of $\mathrm{H}_{2} \mathrm{O}$, and $24.63 \pm$ $4.77 \mathrm{~cm}$ of $\mathrm{H}_{2} \mathrm{O}$, respectively. $p$ value was strongly significant showing a positive correlation between pneumo-peritoneum and cuff pressures. We could see the cuff pressure continuously increasing in successive readings. Post desufflation and prior to extubation, there was a fall in cuff pressure with mean cuff pressure being $17.24+5.32 \mathrm{~cm}$ of $\mathrm{H}_{2} \mathrm{O}$ and $15.27+4.00 \mathrm{~cm}$ of $\mathrm{H}_{2} \mathrm{O}$, respectively, which also suggests that cuff pressures increased with pneumoperitoneum.

Conclusion: Use of $\mathrm{N}_{2} \mathrm{O}$ increases the cuff pressure $\left(31.4+12.54 \mathrm{~cm}_{\text {of }} \mathrm{H}_{2} \mathrm{O}\right)$, especially immediately post-insufflation $\left(35.54+12.06 \mathrm{~cm}\right.$ of $\left.\mathrm{H}_{2} \mathrm{O}\right)$, more so in head low position $\left(36.28+12.13 \mathrm{~cm}\right.$ of $\mathrm{H}_{2} \mathrm{O}$ ). Mean airway pressure (Ppeak) also increased with pneumoperitoneum (22.60 +4.38 $\mathrm{cm}$ of $\mathrm{H}_{2} \mathrm{O}$ ). The regular monitoring of endotracheal tube cuff pressure should be a part of regular safe practice of anesthesia, and use of handy device like hand pressure gauge should be implemented in regular practice where $\mathrm{N}_{2} \mathrm{O}$ is used.

Keywords: Cuff pressure, Endotracheal tube, Laparascopic surgery, $\mathrm{N}_{2} \mathrm{O}$, Pneumo-peritoneum.

Journal of Medical Academics (2020): 10.5005/jp-journals-10070-0052
\end{abstract}

\section{INTRODUCTION}

Laparoscopic surgery is performed under general anesthesia with mechanical ventilation, and a high-volume, low-pressure endotracheal tube with a sealing cuff pressure about $20-30 \mathrm{~cm}$ of $\mathrm{H}_{2} \mathrm{O}$ is commonly used for a proper seal and avoidance of overinflation. $^{1-4}$

There are several significant respiratory system changes during laparoscopic surgery. Abdominal $\mathrm{CO}_{2}$ insufflation, i.e., creation of pneumoperitoneum, elevates the intrathoracic pressure. ${ }^{5,6}$ Also, change in patient position either a head-up or head-down tilt results in a change in pulmonary compliance. ${ }^{7,8}$ However, the impact of these physiologic alterations on endotracheal tube cuff pressure is not yet thoroughly clarified.

Nitrous oxide $\left(\mathrm{N}_{2} \mathrm{O}\right)$ is an inhalational anesthetic that is used with oxygen in the ratio 50:50 is for maintenance of anesthesia if there is no facility of medical air. However, $\mathrm{N}_{2} \mathrm{O}$ increases the intracuff pressure of the tracheal tube due to diffusion of $\mathrm{N}_{2} \mathrm{O}$ in to cuff during general anesthesia. ${ }^{9-11}$ This diffusion is maximum during the first hour of $\mathrm{N}_{2} \mathrm{O}$ anesthesia. Thus, intracuff pressure may increase steadily and reach a level high enough to impede the microcirculation in the tracheal mucosa within 1 hour, ${ }^{12,13}$ which may cause damage to the tracheal tissue. This represents a
${ }^{1}$ Department of Critical Care, Apollo Hospital, Mumbai, Maharashtra, India

${ }^{2}$ Department of Anesthesia, Lokmanya Tilak Municipal General Hospital and Medical College, Mumbai, Maharashtra, India

${ }^{3}$ Department of Anaesthesiology, General Hospital, Jammu and Kashmir, India

Corresponding Author: Shibu Sasidharan, Department of Anaesthesiology, General Hospital, Jammu and Kashmir, India, Phone: +91 7507111992, e-mail: shibusasi@gmail.com

How to cite this article: Narendra HR, Nerurkar A, Sasidharan S. Observational Analysis of Changes in Endotracheal Tube Cuff Pressure During Laparoscopic Surgery. J Med Acad 2020;3(2):46-49.

Source of support: Nil

Conflict of interest: None

major complication of $\mathrm{N}_{2} \mathrm{O}$ use. Thus, pneumoperitoneum, surgical positioning, and use of nitrous oxide can all lead to various changes in cuff pressure.

Laryngotracheal complications are common after tracheal intubation and also during short duration anesthesia. The major

(c) The Author(s). 2020 Open Access This article is distributed under the terms of the Creative Commons Attribution 4.0 International License (https:// creativecommons.org/licenses/by-nc/4.0/), which permits unrestricted use, distribution, and non-commercial reproduction in any medium, provided you give appropriate credit to the original author(s) and the source, provide a link to the Creative Commons license, and indicate if changes were made. The Creative Commons Public Domain Dedication waiver (http://creativecommons.org/publicdomain/zero/1.0/) applies to the data made available in this article, unless otherwise stated. 
symptoms reported after tracheal intubation are sore throat, hoarseness, and dysphagia. ${ }^{9,14}$ Although the pathophysiology of post-intubation airway symptoms is not completely clarified, the mucosal damage that occurs at the cuff level and the cuff's pressure are thought to be essential causative factors for tracheal morbidity. ${ }^{9}$ Endotracheal tube cuff pressures are not routinely measured. It has been verified that palpation of the pilot balloon is inadequate to detect high cuff pressures. ${ }^{15-17}$ Decreased mucosa perfusion of the trachea is due to cuff pressure greater than $30 \mathrm{~cm}$ of $\mathrm{H}_{2} \mathrm{O} .^{18}$

The present study is being carried out to assess the cuff pressure changes in laparoscopic surgeries with nitrous oxide anesthesia and to assess effect of various positions during surgery on cuff pressure.

\section{Materials and Methods}

The prospective observational study was conducted to assess endotracheal cuff pressure changes in laparoscopic surgeries with $\mathrm{N}_{2} \mathrm{O}$ anesthesia and also to observe incidence of any postoperative consequences, such as sore throat, dysphagia, hoarseness of voice, and stridor.

This study was done in a tertiary-level hospital in India. After institutional ethics committee approval, all patients undergoing elective laparoscopic surgeries in various operation theaters were assessed for the below-mentioned inclusion and exclusion criteria. Patients fulfilling all inclusion and exclusion criteria were explained about the study and invited to participate in the study after taking an informed consent.

\section{Inclusion Criteria}

- Adult patient from either gender aged 18-70 years.

- Patient scheduled for elective laparoscopic surgery requiring nitrous oxide anesthesia with endotracheal intubation and controlled ventilation.

- ASA grade I/II.

\section{Exclusion Criteria}

- Any contraindications to use of nitrous oxide.

- Patient having laryngeal diseases and undergoing laryngeal surgeries

- Patient with any type of airway diseases.

- Patients with high risk of pulmonary complications.

All patients were premedicated with Injection glycopyrrolate $0.2 \mathrm{mg}$, injection midazolam 1-1.5 mg, and injection fentanyl 2 $\mu / \mathrm{kg}$ intravenously. Then, each patient was preoxygenated with $100 \% \mathrm{O}_{2}$ for 3 minutes using anesthesia breathing system with circle absorber, and end-tidal carbon dioxide was monitored. Anesthesia was induced with injection propofol at $2-2.5 \mathrm{mg} / \mathrm{kg}$. Neuromuscular blockade was achieved with injection vecuronium $0.1 \mathrm{mg} / \mathrm{kg}$. Each patient was ventilated with $\mathrm{O}_{2}$ and $\mathrm{N}_{2} \mathrm{O}(50: 50)$ for $2 \frac{1}{2}$ minutes followed by $100 \% \mathrm{O}_{2}$ for 30 seconds.

Under direct laryngoscopic vision, orotracheal intubation was achieved. Endotracheal tube size was selected based on the patient sex and build and clinical judgement of the anesthesiologist administering anesthesia. The correct placement of the endotracheal tube was confirmed by direct laryngoscopy, bilateral chest auscultation, and by checking square waveform on capnograph attached to the breathing system. If any patient needed more than one attempt for intubation or had a traumatic intubation, the case was excluded from the study. All patients were mechanically ventilated using circle absorber system and ventilator. Anesthesia was maintained with oxygen, nitrous oxide (50:50), intravenous propofol infusion (50-150 $\mu / \mathrm{kg} /$ minute), and intermittent injection vecuronium. Supplemental analgesia was provided with injection fentanyl $0.5-1 \mu / \mathrm{kg}$ intravenously every hour. Nasogastric tube was inserted in all patients. No pharyngeal packing was done.

Endotracheal cuff was inflated with incremental doses of $0.5 \mathrm{~mL}$ of air to a point where no leak on auscultation on the suprasternal area was noted. Cuff pressure measurement using cuff pressure monitor (Hand pressure gauge) was done at time of first inflation of cuff up to $20-30 \mathrm{~cm}$ of $\mathrm{H}_{2} \mathrm{O}$ and airway pressure along with total amount of air inflated was noted as zero reading. Thereafter, cuff pressure was measured at regular interval of 5 minutes till insufflations. Abdominal insufflation was done in the supine position with the intra-abdominal pressure kept between $10-15 \mathrm{~cm}$ of $\mathrm{H}_{2} \mathrm{O}$. Head-up or head-down position was given as per surgery. Cuff pressures and airway pressures were taken just prior to insufflation, 2 minutes after abdominal insufflation, thereafter every 15 minutes throughout surgery, 2 minutes after desufflation, and prior to extubation. Change in the position of patient throughout the surgery was noted whenever the cuff pressure was measured. All measurements were taken keeping patient's head and neck in the neutral position.

If the cuff pressure exceeded $40 \mathrm{~cm}$ of $\mathrm{H}_{2} \mathrm{O}$, the cuff was deflated to regain pressure of $20-30 \mathrm{~cm} \mathrm{H}_{2} \mathrm{O}$. If cuff pressure decreased with air leak noted as loss of tidal volume or audible leak of gas, the cuff was reinflated with incremental doses of $0.5 \mathrm{~mL}$ of air to a point where no leak on auscultation on the suprasternal area. Total numbers of deflation/inflations events were noted. The maximum tracheal cuff pressures were also recorded in each patient.

\section{Statistical Methods}

Descriptive and inferential statistical analyzes were carried out in the present study. Results on continuous measurements were presented on mean \pm SD (Min-Max), and results on categorical measurements were presented in number (\%). Significance is assessed at $5 \%$ level of significance. The following assumptions on data was made.

\section{Data Analysis}

The statistical software namely SAS 9.2, SPSS 15.0, Stata 10.1, MedCalc 9.0.1,Systat 12.0, and R environment ver.2.11.1 were used for the analysis of the data, and Microsoft word and Excel have been used to generate graphs, tables, etc.

\section{Results}

Table 1 shows mean tracheal cuff pressure of patients during surgery. Here, we could see the cuff pressure at the induction have kept in range of $20-30 \mathrm{~cm}$ of $\mathrm{H}_{2} \mathrm{O}$ has explained in materials and methodology section. In this study, mean tracheal cuff pressure at baseline was $21.10 \pm 6.16$ ( $p$ value of 0.207 ) and prior to insufflation was $21 \pm 7.13$ ( $p$ value of 0.733 ).The cuff pressures at 2 minutes postinsufflation, $P_{15}, P_{30}, P_{45}$, and $P_{60}$ were $31.40 \pm 12.54 \mathrm{~cm}$ of $\mathrm{H}_{2} \mathrm{O}, 25.79$

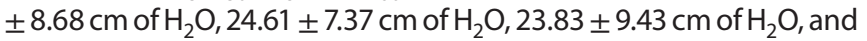
$24.63 \pm 4.77 \mathrm{~cm}$ of $\mathrm{H}_{2} \mathrm{O}$, respectively. $p$ value is strongly significant showing a positive correlation between pneumoperitoneum and cuff pressures. We could see the cuff pressure continuously increasing in successive readings. Post-desufflation and prior to extubation, there was a fall in cuff pressure with mean cuff 
Table 1: Tracheal cuff pressures: an assessment

\begin{tabular}{lccc}
\hline Tracheal cuff pressures & Mean \pm SD & Difference & $p$ value \\
\hline After induction & $21.10 \pm 6.16$ & - & - \\
5 minutes & $20.70 \pm 5.59$ & 0.348 & 0.207 \\
10 minutes & $9.57 \pm 11.59$ & 0.433 & 0.512 \\
15 minutes & $21.00 \pm 7.13$ & 0.667 & 0.638 \\
Prior to insufflation & $21.24 \pm 5.90$ & -0.142 & 0.733 \\
2 minutes post & $31.40 \pm 12.54$ & -10.300 & $<0.001^{* *}$ \\
insufflation & & & \\
15 minutes & $25.79 \pm 8.68$ & -4.685 & $<0.001^{* *}$ \\
30 minutes & $24.61 \pm 7.37$ & -3.514 & $<0.001^{* *}$ \\
45 minutes & $23.83 \pm 9.43$ & -2.909 & $0.022^{*}$ \\
60 minutes & $24.63 \pm 4.77$ & -2.232 & $0.025^{*}$ \\
90 minutes & $23.47 \pm 4.61$ & 0.00 & 1.000 \\
Desufflation & $17.24 \pm 5.32$ & 3.857 & $<0.001^{* *}$ \\
Prior to extubation & $15.27 \pm 4.00$ & 5.828 & $<0.001^{* *}$ \\
\hline
\end{tabular}

Student $t$ test,

+Suggestive significance ( $p$ value: $0.05<p<0.10$ )

${ }^{*}$ Moderately significant ( $p$ value: $0.01<p \leq 0.05$ )

**Strongly significant ( $p$ value: $p \leq 0.01$ )

Table 2: Mean airway pressures: an assessment

\begin{tabular}{lllc}
\hline $\begin{array}{l}\text { Mean airway pres- } \\
\text { sures }\end{array}$ & Mean \pm SD & Difference & p value \\
\hline After induction & $14.97 \pm 3.71$ & - & - \\
5 minutes & $15.18 \pm 3.36$ & -0.076 & 0.587 \\
10 minutes & $16.80 \pm 4.00$ & -0.400 & 0.206 \\
15 minutes & $14.83 \pm 3.66$ & -0.500 & 0.688 \\
Prior to insufflation & $15.84 \pm 3.71$ & -0.871 & $0.002^{* *}$ \\
2 minutes post insuf- & $21.23 \pm 4.62$ & -6.257 & $<0.001^{* *}$ \\
flation & & & \\
15 minutes & $19.83 \pm 3.74$ & -4.857 & $<0.001^{* *}$ \\
30 minutes & $20.06 \pm 4.19$ & -5.086 & $<0.001^{* *}$ \\
45 minutes & $20.00 \pm 4.15$ & -4.788 & $<0.001^{* *}$ \\
60 minutes & $20.05 \pm 3.82$ & -4.349 & $<0.001^{* *}$ \\
90 minutes & $20.71 \pm 3.18$ & -4.059 & $<0.001^{* *}$ \\
Desufflation & $14.87 \pm 2.94$ & 0.100 & 0.797 \\
Prior to extubation & $14.03 \pm 3.23$ & 0.943 & $0.039^{*}$ \\
\hline
\end{tabular}

Student $t$ test

+Suggestive significance ( $p$ value: $0.05<p<0.10$ )

*Moderately significant ( $p$ value: $0.01<p \leq 0.05$ )

**Strongly significant ( $p$ value: $p \leq 0.01$ )

pressure being $17.24 \pm 5.32 \mathrm{~cm}$ of $\mathrm{H}_{2} \mathrm{O}$ and $15.27+4.00 \mathrm{~cm}$ of $\mathrm{H}_{2} \mathrm{O}$, respectively, which again suggest that cuff pressures increased with pneumoperitoneum.

The mean airway pressures characteristics are detailed in Table 2. The mean airway pressures $\left(P_{\text {peak }}\right)$ after induction is $14.97 \pm 3.71 \mathrm{~cm}$ of $\mathrm{H}_{2} \mathrm{O}$. $P_{\text {peak }}$ at 2 minutes post-insufflation, 15 , $30,45,60$, and 90 minutes were $21.23 \pm 4.62 \mathrm{~cm}$ of $\mathrm{H}_{2} \mathrm{O}, 19.83 \pm$ $3.74 \mathrm{~cm}$ of $\mathrm{H}_{2} \mathrm{O}, 20.06 \pm 4.19 \mathrm{~cm}$ of $\mathrm{H}_{2} \mathrm{O}, 20.00 \pm 4.15 \mathrm{~cm}$ of $\mathrm{H}_{2} \mathrm{O}$, $20.05 \pm 3.82 \mathrm{~cm}$ of $\mathrm{H}_{2} \mathrm{O}$, and $20.71 \pm 3.18 \mathrm{~cm}$ of $\mathrm{H}_{2} \mathrm{O}$, respectively. $p$ value was $<0.001$ which is statistically strongly significant. We can notice the increase in $P_{\text {peak }}$ along with increase in cuff pressure throughout surgery. The same is depicted in tabular presentation below.
Table 3: Maximum levels

\begin{tabular}{lccc}
\hline Maximum & No. of patients $(n=70)$ & $\%$ & Mean $\pm S D$ \\
\hline \multicolumn{2}{l}{ Tracheal cuff pressures } & & \\
$<20$ & 7 & 10.0 & $35.54 \pm 12.06$ \\
$20-40$ & 41 & 58.6 & \\
$>40$ & 22 & 31.4 & \\
Mean airway pressures & & \\
$<20$ & 18 & 25.7 & $22.60 \pm 4.38$ \\
$20-40$ & 52 & 74.3 & \\
$>40$ & 0 & 0.0 & \\
\hline
\end{tabular}

Table 4: Maximum from baseline

\begin{tabular}{lcll}
\hline $\begin{array}{l}\text { Maximum from } \\
\text { baseline }\end{array}$ & No. of patients $(n=70)$ & $\%$ & Mean $\pm S D$ \\
\hline \multicolumn{2}{l}{$\begin{array}{l}\text { Tracheal cuff pressures } \\
<20\end{array} \quad 53$} & 75.7 & $13.56 \pm 10.83$ \\
$20-40$ & 16 & 22.9 & \\
$>40$ & 1 & 1.4 & \\
Mean airway pressures & & \\
$<20$ & 70 & 100.0 & $7.47 \pm 3.82$ \\
$20-40$ & 0 & 0.0 & \\
$>40$ & 0 & 0.0 & \\
\hline
\end{tabular}

Table 3 shows maximum cuff pressures and $P_{\text {peak }}$ measured

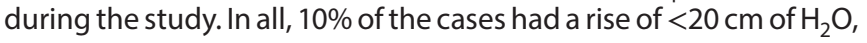
$58.6 \%$ had a rise in the range of $20-40$, and $31.4 \%$ of the patients had a rise of more than $40 \mathrm{~cm}$ of $\mathrm{H}_{2} \mathrm{O}$. Average rise in tracheal cuff pressure was $35.54 \pm 12.06$ which was significantly high enough to compromise tracheal capillary blood supply. In all, $25.7 \%$ of cases had a rise in $P_{\text {peak }}$ of $<20 \mathrm{~mm} \mathrm{Hg}$, and $74.3 \%$ had risen in range of 20-40. Average $P_{\text {peak }}$ measured during the study was $22.60 \pm 4.36$.

Table 4 showing maximum rise in tracheal cuff pressure and airway pressures during the study of 70 patients. In all, $75.7 \%$ of cases had a rise in tracheal cuff pressure of $<20 \mathrm{~cm}$ of $\mathrm{H}_{2} \mathrm{O} ; 22.9 \%$ had risen in the range of $20-40 \mathrm{~cm}^{\circ} \mathrm{H}_{2} \mathrm{O}$, and one case had $>40$ $\mathrm{cm}$ of $\mathrm{H}_{2} \mathrm{O}$ from the baseline. Mean tracheal cuff pressure rise from the baseline was $13.56 \pm 10.83$. Similarly, in all patients, $P_{\text {peak }}$ measured raised below $<20 \mathrm{~mm} \mathrm{Hg}$ and mean $P_{\text {peak }}$ was $7.47+3.82$ from the baseline.

\section{Discussion}

Laparoscopic surgery is performed under general anesthesia with mechanical ventilation, and a high-volume, low-pressure endotracheal tube with a sealing cuff pressure about $20-30 \mathrm{~cm}$ of $\mathrm{H}_{2} \mathrm{O}$ is commonly used for a proper seal and avoidance of overinflation. ${ }^{1-4}$ There are significant changes in cuff pressure during laparoscopic surgery. The factors affecting cuff pressure are abdominal $\mathrm{CO}_{2}$ insufflation, i.e., creation of pneumoperitoneum, change in patient position, either a head-up or head-down tilt, and use of $\mathrm{N}_{2} \mathrm{O}$ with oxygen in the ratio 50:50 for maintenance. Intracuff pressure may increase steadily and reach a level high enough to impede the microcirculation in the tracheal mucosa within 1 hour, ${ }^{12,13}$ which may cause damage to the tracheal tissue.

Studies are lacking in regard to the combined effect on endotracheal cuff pressure comparing $\mathrm{N}_{2} \mathrm{O}$ anesthesia, change in position, and abdominal insufflation, i.e., pneumoperitoneum. This study was designed to find that correlation. 
This is a prospective observational study conducted on 70 patients who are undergoing.

In our study, the base line cuff pressure was same in both groups, which was in a proposed range of $20-30 \mathrm{~cm}$ of $\mathrm{H}_{2} \mathrm{O}$. We found that there was statistically significant increase in cuff pressure in both groups with time till extubation. Cuff pressure changes started early and increased progressively with time. Most of the patients in our study had the deflation events at 2 minutes and 30th min. This is reflected by subsequent cuff pressures being similar to baseline ranges because the cuff pressures were monitored through the surgery and intervened if pressures went more than $40 \mathrm{~cm}$ of $\mathrm{H}_{2} \mathrm{O}$. However, the deflation events were more in group II. These findings are consistent with the study by Manissery et al., and they found that increase in cuff pressure was maximum during first hour of surgery till the equilibrium is reached. ${ }^{19}$ When changes in cuff pressures were compared to change in position, there was no statistically significant difference observed. However, clinically, the percentage of deflation events was more in head low group (40\%) when compared to head high group (26\%). As stated earlier, this is because of increased cuff pressure in head low position. The total number of air leak events was higher in group II (16\%) than group I (6.7\%). This can be because of frequent measurement of cuff pressure can lead to loss of cuff pressure and causing air leak. An experimental study conducted by Asai et al., ${ }^{20}$ found that there can be loss of pressure up to $6.6 \mathrm{~cm}$ of $\mathrm{H}_{2} \mathrm{O}$ with frequent measurements, more so is noticed when continuous monitoring is used.

\section{Conclusion}

Our study helps us to conclude that that use of nitrous oxide increases the cuff pressure $\left(31.4+12.54 \mathrm{~cm}\right.$ of $\left.\mathrm{H}_{2} \mathrm{O}\right)$, especially immediately post-insufflation $\left(35.54+12.06 \mathrm{~cm}\right.$ of $\left.\mathrm{H}_{2} \mathrm{O}\right)$ and more so in head low position $\left(36.28+12.13 \mathrm{~cm}\right.$ of $\left.\mathrm{H}_{2} \mathrm{O}\right)$. Mean airway pressure (Ppeak) also increased with pneumoperitoneum $(22.60+4.38 \mathrm{~cm}$ of $\mathrm{H}_{2} \mathrm{O}$ ). The regular monitoring of endotracheal tube cuff pressure should be a part of regular safe practice of anesthesia, and use of handy device such as hand pressure gauge should be implemented in regular practice of anesthesia where $\mathrm{N}_{2} \mathrm{O}$ is used. The study subject itself draws attention to an often neglected area and is clinically relevant with scope for change in practice in the future.

\section{Limitations}

- Bigger sample size could have added power to the study.

- A control group in which $\mathrm{N}_{2} \mathrm{O}$ was not given could have made results available for comparison.

- $\mathrm{N}_{2} \mathrm{O}$ and static table position could have been a control.

\section{ACKNOWLedgments}

The authors would like to thank all the subjects who consented to participate in this study.

\section{References}

1. Dullenkopf A, Schmitz A, Frei M, et al. Air leakage around endotracheal tube cuffs. Eur J Anaesthesiol 2004;21(6):448-453. DOI: 10.1097/00003643-200406000-00006.

2. Al-Metwalli RR, Al-Ghamdi AA, Mowafi $H A$, et al. Is sealing cuff pressure, easy, reliable and safe technique for endotracheal tube cuff inflation?: a comparative study. Saudi J Anaesth 2011;5(2):185-189. DOI: $10.4103 / 1658-354 X .82795$.
3. Seegobin RD, van Hasselt GL. Endotracheal cuff pressure and tracheal mucosal blood flow: endoscopic study of effects of four large volume cuffs. Br Med J (Clin Res Ed) 1984;288(6422):965-968. DOI: 10.1136/ bmj.288.6422.965http://www.ncbi.nlm.nih.gov/pubmed/6423162. Accessed December 5, 2016.

4. Joh S. Impairment of tracheal mucosal blood flow by endotracheal tube cuffs and its recovery. A study on changes in blood flow and partial pressure of oxygen in tracheal mucosa. Osaka Daigaku Shigaku Zasshi 1986;31(2):334-350. http://www.ncbi.nlm.nih.gov/ pubmed/3469384. Accessed December 5, 2016.

5. Rauh R, Hemmerling TM, Rist M, et al. Influence of pneumoperitoneum and patient positioning on respiratory system compliance. J Clin Anesth 2001;13(5):361-365. DOI: 10.1016/S0952-8180(01)00286Ohttp://www.ncbi.nlm.nih.gov/pubmed/11498317. Accessed December 5, 2016.

6. Sprung J, Whalley DG, Falcone T, et al. The impact of morbid obesity, pneumoperitoneum, and posture on respiratory system mechanics and oxygenation during laparoscopy. Anesth Analg 2002;94(5):13451350. DOI: 10.1097/00000539-200205000-00056http://www.ncbi. nlm.nih.gov/pubmed/11973218. Accessed December 5, 2016.

7. Wilcox S, Vandam LD. Alas, poor Trendelenburg and his position! A critique of its uses and effectiveness. Anesth Analg 1988;67(6):574578. http://www.ncbi.nlm.nih.gov/pubmed/3288005. Accessed December 5, 2016.

8. Nguyen NT, Wolfe BM. The physiologic effects of pneumoperitoneum in the morbidly obese. Ann Surg 2005;241(2):219-226. DOI: 10.1097/01.sla.0000151791.93571.70http://www.ncbi.nlm.nih.gov/ pubmed/15650630. Accessed December 5, 2016.

9. Combes X, Schauvliege F, Peyrouset O, et al. Intracuff pressure and tracheal morbidity: influence of filling with saline during nitrous oxide anesthesia. Anesthesiology 2001;95(5):1120-1124. DOI: 10.1097/00000542-200111000-00015. http://www.ncbi.nlm.nih.gov/ pubmed/11684980. Accessed December 5, 2016.

10. Leonardo Cárpio Peña E, Montoya de Gregori W, Piccinini Filho L, Edson Vieira J, Andrade da Silva Telles Mathias L. Determinação de Volumes e Pressões de Balonetes de Tubos Traqueais Insuflados com Ar Ambiente ou Óxido Nitroso * Volume and Pressure of Tracheal Tube Cuffs Filled with Air or Nitrous Oxide.

11. Mosby EL, Schelkun PM, Vincent SK. Nitrous oxide use and endotracheal tube rupture. Anesth Prog 1988;35(1):14-16. http:// www.ncbi.nlm.nih.gov/pubmed/3422793. Accessed December 5, 2016.

12. Raeder JC, Borchgrevink PC, Sellevold OM. Tracheal tube cuff pressures. Anaesthesia 2007;40(5):444-447. DOI: 10.1111/j.13652044.1985.tb10846.x.

13. Fujiwara S, Noguchi A, Nakamura Y, et al. Diffusion of nitrous oxide through endotracheal tube cuffs. Biomed Res 2016;27(1):40-45.

14. Mandoe H, Nikolajsen L, Lintrup U, et al. Sore Throat After Endotracheal Intubation 1992. 897-900.

15. Lizy BC, Swinnen W, Labeau S, et al. Cuff pressure of endotracheal tubes after changes in body position in critically ill patients treated with mechanical ventilation. Am J Crit Care 2014;23(1):e1-e8. DOI: 10.4037/ajcc2014489.

16. Umi C, Road NZ, Arbor A, Information to users.

17. Sultan $P, C$ arvalho $B$, Rose BO, et al. Endotracheal tube cuff pressure. ASA Abstr 2004;21(11):11-12. http://www.asaabstracts.com/strands/ asaabstracts/abstract.htm;jsessionid=7EC17BCCB0E98687575CA8A D89EF33F8? year $=2004$ \&index $=8$ \&absnum $=397$.

18. Israel B, Medical D, Endotracheal Tube Cuffs: 51-58.

19. Manissery J, Joseph V, Shenoy, et al. Endotracheal tube cuff pressures during general anesthesia while using air vs a $50 \%$ mixture of nitrous oxide and oxygen as inflating agents. Indian J Anaesthe 2007;51(1):24-27.

20. Asai T, Shingu K. Leakage of fluid around high-volume, low-pressure cuffs: a comparison of four tracheal tubes. Anaesthesia 2001;56(1):3842. DOI: 10.1046/j.1365-2044.2001.01718.x. 